\title{
Role of Water-Gas-Shift Reaction in Fischer- Tropsch Synthesis on Iron Catalysts: A Review
}

Dragomir B. Bukur*, 1,2 , Branislav Todic ${ }^{1}$, Nimir Elbashir ${ }^{1}$

${ }^{1}$ Chemical Engineering Program, Texas A\&M University at Qatar, PO Box 23874, Doha, Qatar

${ }^{2}$ Artie McFerrin Department of Chemical Engineering, Texas A\&M University, 3122 TAMU, College Station, Texas 77843, United States

*Corresponding author: Tel.: +974-4423-0134. Fax: +974-4423-0065.

Email: dragomir.bukur@qatar.tamu.edu 


\begin{abstract}
Water-gas-shift (WGS) reaction plays a significant role in industrial application of FischerTropsch synthesis (FTS) for coal-to-liquid (CTL) processes with iron-based catalysts. This reaction provides necessary hydrogen for synthesis gas with low $\mathrm{H}_{2} / \mathrm{CO}$ molar ratio, and has influence on concentrations of reactants, water and carbon dioxide, which in turn has effect on product distribution, rate of FTS and catalyst deactivation. We provide information on the effect of process conditions $\left(\mathrm{H}_{2} / \mathrm{CO}\right.$ feed ratio, reaction temperature and pressure $)$, syngas conversion, and catalyst composition and activation procedure on the WGS activity. $\mathrm{H}_{2} / \mathrm{CO}$ consumption (or usage) ratio and the exit $\mathrm{H}_{2} / \mathrm{CO}$ ratio vary with conversion and the extent of WGS reaction. The extent of variation is much greater for $\mathrm{H}_{2} / \mathrm{CO}$ feed ratios greater than 1.7 , than it is for the $\mathrm{CO}$ rich syngas $\left(\mathrm{H}_{2} / \mathrm{CO}=0.5-1\right)$. This in turn places limits on maximum practical single pass conversion which can be achieved with different feed compositions and results in different types of operation (low single pass conversion with tail gas recycle, and high once through single pass conversion).
\end{abstract}

Keywords: Fischer-Tropsch synthesis; water-gas-shift reaction, iron catalyst, product distribution, fixed bed reactor, slurry phase reactors. 


\section{Introduction}

Fischer-Tropsch Synthesis (FTS) reaction is a key part of technology to convert natural resources, such as coal, natural gas and biomass, into liquid hydrocarbon fuels. FTS is a heterogeneous reaction discovered in the early twentieth century [1]. Reactants, carbon-monoxide and hydrogen (syngas), are converted to an array of hydrocarbons (mainly n-paraffins and olefins), and FTS reaction can be described by the following stoichiometry:

$$
\mathrm{CO}+\left(\frac{m}{2 n}+1\right) \mathrm{H}_{2} \stackrel{r_{1}}{\longrightarrow} \frac{1}{n}\left(C_{n} H_{m}\right)+H_{2} \mathrm{O} \quad \text { FTS }
$$

The catalysts of choice for industrial FTS are cobalt and iron. If the raw material is coal, then the preferred catalyst is iron $[2,3]$. One of the main features of iron FTS catalysts is their watergas-shift (WGS) activity. WGS reaction can be presented as:

$$
\mathrm{CO}+\mathrm{H}_{2} \mathrm{O} \stackrel{r_{2}}{\longleftrightarrow} \mathrm{CO}_{2}+\mathrm{H}_{2}
$$

The WGS reaction provides additional hydrogen for FTS, which is needed in the case of coalderived syngas. Coal-derived syngas normally has a $\mathrm{H}_{2} / \mathrm{CO}$ ratio below 2 , the latter being an approximate stoichiometric $\mathrm{H}_{2} / \mathrm{CO}$ ratio (i.e. $\mathrm{m} / \mathrm{n}=2$ ) needed to produce hydrocarbons according to equations (1).

The main objectives for industrial FTS plants are to achieve efficient utilization, high productivity, long term operation and high selectivity to $\mathrm{C}_{5+}$ hydrocarbons and low methane selectivity. Kinetics of various parallel reactions (FTS, WGS and olefin secondary reactions) determines the overall selectivity of FTS products. Proper selection of process and syngas feed conditions is essential in achieving activity, stability and selectivity targets in commercial FTS reactors. With Fe-based catalysts the effect of WGS is very significant. This reaction affects concentrations (partial pressures) of $\mathrm{CO}, \mathrm{H}_{2}, \mathrm{CO}_{2}$ and $\mathrm{H}_{2} \mathrm{O}$ in the system, which in turn has an 
impact on kinetics of both primary FTS and 1-olefin secondary reactions and thus the product distribution.

In this work we focus on the role of WGS in FTS and review available information on the effect of process conditions on the WGS activity, and the impact of WGS reaction on selection of process conditions used in industrial practice and reactor design considerations.

This paper is dedicated to Professors Mark Dry and Hans Schulz, two giants in the field of FTS catalysis, who have made pioneering contributions to our knowledge about various aspects of industrial applications of FTS and its fundamentals.

\section{Measures of WGS Activity, Stoichiometric Constraints and Equilibrium Calculations}

\subsection{Measures of WGS Activity and Stoichiometric Constraints}

The extent of WGS reaction, or WGS activity, has been expressed in terms of: (1) magnitude of $\mathrm{H}_{2} / \mathrm{CO}$ usage ratio, $\mathrm{U}$; (2) $\mathrm{CO}_{2}$ selectivity; (3) partial pressure quotient $P Q_{W G S}=P_{\mathrm{CO}_{2}} P_{\mathrm{H}_{2}} / P_{\mathrm{CO}} P_{\mathrm{H}_{2} \mathrm{O}}$ or $P_{W G S}=P_{\mathrm{CO}_{2}} /\left(P_{\mathrm{CO}_{2}}+P_{\mathrm{H}_{2} \mathrm{O}}\right)$; or (4) as ratio of WGS rate to FTS rate, $\mathrm{r}_{\mathrm{WGS}} / \mathrm{r}_{\mathrm{FTS}}$. First we introduce definitions and provide some useful relations between different variables and conversions of reactants.

Fractional conversion of a reactant $\left(\mathrm{X}_{\mathrm{i}}\right)$, is defined as:

$$
\mathrm{X}_{\mathrm{i}}=\left(\frac{n_{i}^{0}-n_{i}}{n_{i}^{0}}\right)
$$

where: $n_{i}^{0}=$ molar flow rate of $\mathrm{i}$ entering the reactor; $n_{i}=$ molar flow rate of $\mathrm{i}$ leaving the reactor, $\mathrm{i}=\mathrm{H}_{2}$ or $\mathrm{CO}$. 
Usage ratio is defined as a ratio of moles of $\mathrm{H}_{2}$ consumed and moles of $\mathrm{CO}$ consumed, and can be expressed in terms of reactant conversions, and $\mathrm{H}_{2}$ to $\mathrm{CO}$ molar ratio in the feed, $F=n_{H_{2}}^{0} / n_{C O}^{0}:$

$$
U=F \frac{X_{H_{2}}}{X_{C O}}
$$

In FTS it is common to express conversion in terms of consumption of $\mathrm{H}_{2}+\mathrm{CO}$, since the rate of syngas consumption is independent of the extent of WGS reaction. From definitions of reactant conversions and usage ratio (Equations 3 and 4) one can obtain the following relations between the syngas conversion, $X_{{\mathrm{CO}+\mathrm{H}_{2}}_{2}}$, and the conversions for $\mathrm{H}_{2}$ and $\mathrm{CO}$ :

$$
\begin{gathered}
X_{H_{2}+C O}=X_{H_{2}} \frac{F(1+U)}{U(1+F)} \\
X_{H_{2}+C O}=X_{C O} \frac{(1+U)}{(1+F)}
\end{gathered}
$$

If the usage ratio is not reported directly, one can use Equations (4) to (6) to calculate it from reported values of any two values of conversions $\left(X_{\mathrm{H}_{2}}, X_{\mathrm{CO}}\right.$ or $\left.X_{\mathrm{H}_{2}+\mathrm{CO}}\right)$ and F. Next we describe stoichiometric limitations on the usage ratio arising from the stoichiometry of reactions (1) and (2). First we rewrite Eq (1) in a more convenient form as:

$$
\mathrm{CO}+\left(\frac{\gamma}{2}+1\right) \mathrm{H}_{2} \stackrel{\eta_{1}}{\longrightarrow} \frac{1}{n}\left(\mathrm{CH}_{\gamma}\right)_{n}+\mathrm{H}_{2} \mathrm{O}
$$

where: $\gamma=\mathrm{m} / \mathrm{n}$ (average $\mathrm{H} / \mathrm{C}$ ratio in hydrocarbon products). Typically, $\gamma=2.1-2.4$.

If there is no WGS activity then the usage ratio from Eq. (7) is: $U=1+\gamma / 2$. In the other extreme if all water formed in FTS reaction is consumed by WGS (high WGS activity), the overall reaction can be written is: 


$$
2 \mathrm{CO}+\frac{\gamma}{2} \mathrm{H}_{2}=\frac{1}{n}\left(\mathrm{CH}_{\gamma}\right)_{n}+\mathrm{CO}_{2}
$$

and the corresponding usage ratio is: $\mathrm{U}=\gamma / 4$. Thus, the usage ratio values are constrained by stoichiometry and the extent of WGS reaction to:

$$
\gamma / 4 \leq \mathrm{U} \leq 1+\gamma / 2
$$

The magnitude of the usage ratio, subject to the above constraint, provides indication of the extent of WGS reaction (or WGS activity), low values of U are indicative of high WGS activity, whereas high values correspond to low WGS activity.

The complete utilization of feed gas is possible only when the usage ratio equals the $\mathrm{H}_{2} / \mathrm{CO}$ feed ratio, i.e. when $\mathrm{U}=\mathrm{F}$. If $\mathrm{U}<\mathrm{F}$ then the $\mathrm{CO}$ is the limiting reactant and the maximum possible syngas conversion is obtained from Eq. (6) with $\mathrm{X}_{\mathrm{CO}}=1$, yielding:

$$
\left(X_{\mathrm{H}_{2}+\mathrm{CO}}\right)_{\max }=\frac{(1+U)}{(1+F)} \quad(\mathrm{U}<\mathrm{F})
$$

On the other hand if $\mathrm{U}>\mathrm{F}$ then $\mathrm{H}_{2}$ is the limiting reactant and the maximum possible syngas conversion is obtained from Eq. (5) with $X_{H_{2}}=1$, yielding

$$
\left(X_{\mathrm{H}_{2}+\mathrm{CO}}\right)_{\max }=\frac{F(1+U)}{U(1+F)} \quad(\mathrm{U}>\mathrm{F})
$$

If the partial pressures of inorganic species at the reactor exit are reported they can be used to estimate the extent of WGS activity. Partial pressure quotient value $P Q_{W G S}=P_{\mathrm{CO}_{2}} P_{\mathrm{H}_{2}} / P_{\mathrm{CO}} P_{\mathrm{H}_{2} \mathrm{O}}$ can be compared to the equilibrium constant value for the WGS reaction, $\mathrm{K}_{\mathrm{WGS}}$ (T), to determine the extent of the WGS activity. If $\mathrm{PQ}_{\mathrm{WGS}}$ value is close to that of $\mathrm{K}_{\mathrm{WGS}}$, this would be indicative of high WGS activity, whereas if $\mathrm{PQ}_{\mathrm{wGS}} \ll<\mathrm{K}_{\mathrm{WGS}}$ this would imply low WGS activity. Likewise 
the magnitude of $P_{W G S}=P_{\mathrm{CO}_{2}} /\left(P_{\mathrm{CO}_{2}}+P_{\mathrm{H}_{2} \mathrm{O}}\right)$ provides the same qualitative information; if $\mathrm{P}_{\mathrm{WGS}}$ $<<1$ the WGS activity is low, whereas if $\mathrm{P}_{\mathrm{WGS}} \approx 1$ the WGS activity is high. However, values of partial pressures are often not reported, whereas a value of so called $\mathrm{CO}_{2}$ selectivity is usually reported. $\mathrm{CO}_{2}$ selectivity represents a fraction of $\mathrm{CO}$ converted to $\mathrm{CO}_{2}$ by WGS reaction, i.e.

$$
S_{\mathrm{CO}_{2}}=\frac{r_{\mathrm{CO}_{2}}}{\left(-r_{\mathrm{CO}}\right)}=\frac{r_{2}}{r_{1}+r_{2}}
$$

where: $r_{1}=r_{\text {FTS }}$ and $r_{2}=r_{\text {WGS }}$ are intrinsic rates of reactions 1 and 2 (as per Equations 1 and 2); $r_{\mathrm{CO}_{2}}=\mathrm{r}_{2}$ is the rate of $\mathrm{CO}_{2}$ formation (i.e. rate of WGS reaction); $\left(-\mathrm{r}_{\mathrm{CO}}\right)=$ rate of $\mathrm{CO}$ disappearance.

If there is no $\mathrm{CO}_{2}$ and water in the feed it can be shown that $\mathrm{P}_{\mathrm{WGS}}$ and $\mathrm{CO}_{2}$ selectivity, $\mathrm{S}_{\mathrm{CO}_{2}}$ , are related as follows:

$$
P_{W G S}=\frac{S_{\mathrm{CO}_{2}}}{1-S_{\mathrm{CO}_{2}}}
$$

From the definition of PwGs and Eq. (13) it can be concluded that the maximum possible value of $\mathrm{CO}_{2}$ selectivity is 0.5 . Thus, small values of $\mathrm{CO}_{2}$ selectivity indicate low WGS activity, whereas $S_{\mathrm{CO}_{2}} \approx 0.5$ would be indicative of high WGS activity.

\subsection{Comparison between equilibrium calculations and experimental}

\section{data}

WGS reaction is a reversible reaction and when the reaction is very fast it will reach equilibrium. The usage ratio can be predicted from equilibrium calculations and reaction stoichiometry as described in $[4,5]$. The relevant equations are:

$$
U=[(1+\gamma / 2) x-y] /(x+y)
$$




$$
\begin{gathered}
X_{\mathrm{H}_{2}+\mathrm{CO}}=(2+\gamma / 2) x /(1+F) \\
K_{W G S}=\left(\frac{P_{\mathrm{CO}_{2}} P_{\mathrm{H}_{2}}}{P_{\mathrm{CO}} P_{\mathrm{H}_{2} \mathrm{O}}}\right)_{e q}=\frac{y[F+y-(1+\gamma / 2) x]}{(x-y)(1-x-y)}
\end{gathered}
$$

where: $\mathrm{x}=$ moles of $\mathrm{H}_{2} \mathrm{O}$ formed in FTS reaction, $\mathrm{y}=$ moles of $\mathrm{CO}_{2}$ formed by WGS.

The equilibrium constant for the WGS reaction as a function of temperature is given by [6].

$$
K_{W G S}=0.0132 \exp (4578 / T)
$$

For a given temperature ( $\mathrm{T}$ in $\mathrm{K}), \mathrm{F}, \gamma$ and syngas conversion one can calculate the corresponding usage ratio as follows: calculate $\mathrm{x}$ from Eq. (15) and $\mathrm{K}_{\mathrm{WGS}}$ from (17), then y from Eq. (16) and finally U from Eq. (14).

The molar ratio of $\mathrm{H}_{2}$ and $\mathrm{CO}$ at the exit of the reactor, E, can be calculated from definitions of conversions as follows:

$$
E=\left[F(1+U)-U(1+F) X_{H_{2}+C O}\right] /\left[(1+U)-(1+F) X_{H_{2}+C O}\right]
$$

Substitution of the numerical value of $\mathrm{U}$ based on equilibrium calculations described above, into Eq. (18) yields the predicted value of the exit $\mathrm{H}_{2} / \mathrm{CO}$ ratio, which can be compared with experimental values under the same conditions. Experimental value of $\mathrm{E}$ can be calculated from Eq. (18) using the experimental value of U, or from Eq. (19) below which utilizes values of reactant conversions:

$$
E=F\left(1-X_{H_{2}}\right) /\left(1-X_{C O}\right)
$$

Comparison between predictions of $\mathrm{U}$ and $\mathrm{E}$ from equilibrium calculations and experimental data corresponding to low and medium temperature FTS $(\mathrm{T}=493-543 \mathrm{~K})$ with fused iron and precipitated iron catalysts is shown in Figures 1 and 2, respectively. Equilibrium predictions are shown as solid lines which are calculated assuming $\mathrm{T}=523 \mathrm{~K}$ and $\gamma=2.2$. It should be noted that 
equilibrium predictions are not sensitive to temperature, in the range 493-543 $\mathrm{K}$, and $\gamma$ values between 2.2 and 2.4. Numerical value of the WGS equilibrium constant, calculated from Eq (17), is between 60 and 142 (for temperatures between 493 and $543 \mathrm{~K}$ ) and calculated values of $\mathrm{U}$ and E are not sensitive to temperature within this temperature range. Also, equilibrium values are not a function of total pressure. Thus, we are showing experimental data obtained at different temperatures and pressures in these figures for comparison with equilibrium predictions. Also, this allows us to cover a wider range of syngas conversions. Dashed lines in Figures 1 and 2 depict trends in experimental data.

Usage ratio calculated assuming WGS equilibrium is low $(\mathrm{U} \approx \gamma / 4=0.55)$ at low conversions and is almost independent of the $\mathrm{H}_{2} / \mathrm{CO}$ feed ratio. As syngas conversion increases the usage ratio increases first slowly and then more rapidly at higher conversions (Figures 1a and 2a) reaching the value of the corresponding feed ratio $\mathrm{F}$ at $X_{\mathrm{H}_{2}+\mathrm{CO}}=1$. However, experimental data at low conversions show a different trend. At low conversions values of the usage ratio are significantly higher than the minimum value of 0.55 since the WGS reaction is not at equilibrium under these conditions $(\mathrm{T}=493-543 \mathrm{~K})$. The usage ratio is governed by kinetics of the WGS reaction, and at low conversions the partial pressure of water is low and consequently the rate of WGS reaction is low resulting in high values of the usage ratio. It is expected that at very low conversions the usage ratio will approach its stoichiometric limit of $U=1+\gamma / 2$ (i.e. $U=2.1$ ). Data in Fig. 2a with precipitated iron catalyst (100 Fe/5 Cu/4.2 K/25 $\mathrm{SiO}_{2}$ in parts by weight) clearly show this trend (data for $X_{\mathrm{H}_{2}+\mathrm{CO}}<20 \%$ ). As the conversion increases, the partial pressure of water increases and the usage ratio decreases, and after reaching a minimum it begins to increase (the value of syngas conversion at which this occurs is dependent on the $\mathrm{H}_{2} / \mathrm{CO}$ feed ratio) since the WGS reaction approaches equilibrium at higher conversions (e.g. data for $\mathrm{F}=1.81$ in Fig. 1a at $X_{\mathrm{H}_{2}+\mathrm{CO}} \approx 60 \%$ ). 
It is noted that high syngas conversions can't be achieved experimentally under all conditions (F, $T$ and $P$ ), since the maximum syngas conversion is limited when $U \neq F$ as per Eqs. (10) and (11).

Equilibrium calculations predict that the exit $\left(\mathrm{H}_{2} / \mathrm{CO}\right)$ ratio increases with increase in syngas conversion, and with the $\left(\mathrm{H}_{2} / \mathrm{CO}\right)$ feed ratio (Figs. $1 \mathrm{~b}$ and $\left.2 \mathrm{~b}\right)$. Experimental data with both fused and precipitated catalyst follow this trend. It should be noted that equilibrium and experimental data show that the exit ratio does not change significantly with syngas conversion (up to $\sim 80 \%$ ) for the $\mathrm{CO}$ rich syngas $(\mathrm{F} \approx 0.67)$ and becomes high only at very high syngas conversions $(>$ $90 \%$ ), whereas the exit ratio increases faster and has higher values as the syngas feed ratios increases (c.f. results for $F=1.81$ in Fig. $1 b, F=2$ in Fig. $2 b$ ). In a stirred tank reactor (perfectly mixed flow reactor) the exit ratio is the same as the $\mathrm{H}_{2} / \mathrm{CO}$ ratio in the reactor itself, and this has a great impact on product selectivity in low temperature FTS [10-12]. High reactor $\mathrm{H}_{2} / \mathrm{CO}$ ratio favors chain termination reactions and results in high selectivity to $\mathrm{CH}_{4}$ and low molecular weight hydrocarbons $\left(\mathrm{C}_{2}-\mathrm{C}_{4}\right)$, which is undesirable from an economic point of view.

Data illustrating comparison between equilibrium predicted values and experimental ones (U, PQwgs and E) have been reported previously $[4,5]$. The trends shown in Figures 1 and 2 are consistent with these studies. From all these studies it is evident that variations in $\mathrm{U}$ and $\mathrm{E}$ with conversion are less pronounced when the $\mathrm{CO}$ rich feed gas is used $(\mathrm{F}=0.67-1)$ relative to those with $\mathrm{F}=1.8-2$. For the $\mathrm{CO}$ rich syngas feed the exit ratio is relatively low and $\mathrm{U} \approx \mathrm{F}$ even at high syngas conversions (up to $\sim 90 \%$ ).

3. Effect of process conditions, catalyst composition and activation procedure on the WGS activity

\subsection{Effect of temperature}


Results from experiments in our laboratory with precipitated iron catalyst (Ruhrchemie catalyst with nominal composition $100 \mathrm{Fe} / 5 \mathrm{Cu} / 4.2 \mathrm{~K} / 25 \mathrm{SiO}_{2}$ by weight) in a stirred tank slurry reactor are shown in Fig. 3. The usage ratio decreases with an increase in conversion (at constant temperature) or with an increase in temperature (at constant conversion) for $\mathrm{F}=0.67$ (Fig. 3a). At higher conversions the effect of temperature is less pronounced. Similar trends are observed with $\mathrm{F}=2$ (Fig. 3b) except that at $533 \mathrm{~K}$, the usage ratio starts to increase for $X_{\mathrm{H}_{2}+\mathrm{CO}}>45 \%$. The increase in WGS activity (decrease in U) with increase in temperature (at constant conversion) is a kinetic effect. However, as conversion increases the WGS reaction approaches equilibrium and the effect of temperature on the usage ratio diminishes.

\subsection{Effect of pressure}

Figure 4 illustrates the effect of pressure on the usage ratio for two different feed ratios. Usage ratio is lower (higher WGS activity) at a lower pressure at constant syngas conversion, for both F $=0.67$ and $\mathrm{F}=2$. The WGS equilibrium is not a function of pressure, and the observed trend is related to kinetics of the WGS reaction. All proposed rate equations, but one, for the WGS reaction (see Table 3 in Section 5) do not indicate that the rate increases with decrease in pressure, and the observed trend is difficult to explain without detailed numerical simulations.

Available data in the literature generally do not provide sufficient details to illustrate the effect of temperature and/or pressure, at a constant conversion, on the extent of WGS reaction. Selected data with fused and precipitated iron catalysts which illustrate the effects of temperature and pressure on the usage ratio are shown in Table 1. These data are in agreement with trends shown in Figures 3 and 4, i.e. the usage ratio decreases with increase in temperature or decrease in pressure at nearly constant syngas conversion (in all cases $X_{\mathrm{H}_{2}+\mathrm{CO}}<60 \%$ ). 


\subsection{Effect of feed composition and recycle}

Govender et al. [14] presented results which illustrate the effect of feed ratio $(\mathrm{F}=1.08-2.01)$ and recycle ratio (approximate range $0.8-1.8$ ) on the exit $\mathrm{H}_{2} / \mathrm{CO}$ ratio and $\mathrm{CO}$ conversion based on experiments in a stirred tank slurry reactor with Sasol's catalyst for low temperature FTS (LTFT) at $513 \mathrm{~K}, 2 \mathrm{MPa}, 5 \mathrm{NL} / \mathrm{g}$-cat/h. Water was removed from the tail gas before it was returned to the reactor inlet. They found that the usage ratio was approximately 1.4 , and $\mathrm{CO}_{2}$ selectivity is $20-25 \%$ for the conditions employed. The exit ratio was less than the feed ratio for $\mathrm{F}<1.4(\mathrm{~F}=$ 1.08), and $\mathrm{E}>\mathrm{F}$ for $\mathrm{F}>1.4(\mathrm{~F}=1.5$ and 2.01). The single pass $\mathrm{CO}$ conversion was $\sim 30-45 \%$ (increasing with increase in F) without recycle. Recycling did not have much effect on the single pass conversion up to $\mathrm{F}=1.5$, but was higher for $\mathrm{F}=2.01(\sim 53-55 \%$ with recycle vs. $\sim 45 \%$ without recycle). As expected the overall conversion increased with increase in recycle ratio, $\mathrm{R}$, and again the increase of overall conversion was higher for feeds with higher $\mathrm{H}_{2} / \mathrm{CO}$ ratio. The highest overall CO conversion ( $90 \%)$ was obtained with $\mathrm{F}=2.01$ and $\mathrm{R}=1.76$.

\subsection{Effect of catalyst composition}

Common promoters for Fe-based FT catalysts are: alkali metal (chemical promoter), copper (reduction promoter) and silica or alumina (structural promoters). Potassium has a significant effect on both FTS activity and hydrocarbon product distribution (increase in chain growth probability, high olefin content via inhibition of secondary hydrogenation reactions), and it increases catalyst deactivation rate via carbon deposition $[10,15,16]$. Researchers at the US Bureau of Mines have reported that potassium enhances the WGS activity of different types of Fe based catalysts (fused, precipitated, sintered and cemented) [17, 18]. This finding was confirmed in subsequent studies with Fe catalysts of different compositions [19-23]. In some studies it was 
found that WGS goes through a maximum as a function of $\mathrm{K}$ loading [24, 25], but this was accompanied by a significant decrease in FTS activity at high $\mathrm{K}$ loadings (> $1 \mathrm{wt} . \%$ of total mass of the catalyst) due to carbon deposition. Apparently the WGS activity is also adversely affected by carbon deposition. In conclusion, there is a clear evidence that addition of K enhances the WGS activity in the absence of catalyst deactivation by carbon deposition, but the mechanism for promotion is not known.

Bukur et al. [20] reported that addition of $\mathrm{Cu}$ to unpromoted precipitated Fe catalyst (100 Fe/3 $\mathrm{Cu}$ by mass) increases the WGS activity, which is consistent with its role as an active catalytic species in low temperature WGS catalysts [26, 27].

\subsection{Effect of activation procedure on WGS reaction}

Before FTS a catalyst precursor is subjected to a pretreatment, the purpose of which is to bring the catalyst into an active form for FTS. The common pretreatment (activation) procedures with Fe catalysts include: $\mathrm{H}_{2}$ reduction, $\mathrm{CO}$ reduction or activation in synthesis gas $[10,15,28]$. The use of different activation procedure may have a significant effect on the catalyst performance (activity, stability and selectivity) during FTS, and has effect on the WGS activity. The effect of activation procedure on the catalyst performance has been studied extensively in our laboratory at Texas A\&M University with $\mathrm{Fe} / \mathrm{Cu} / \mathrm{K}$ catalysts $[28,29]$ and $\mathrm{Fe} / \mathrm{Cu} / \mathrm{K} / \mathrm{SiO}_{2}$ catalysts $[30,31]$ and results illustrating the effect of activation procedure on the WGS activity are summarized in Table 2.

The WGS activity, measured by values of the usage ratio and partial pressure quotient, was higher after hydrogen reductions than after $\mathrm{CO}$ or syngas activations, although the effect of activation conditions is relatively small. The reasons for this behavior are not well understood since the nature of active form of iron for the WGS reaction during FTS is still unknown, and the 
working catalysts consists of a mixture of iron phases (carbides, magnetite, metallic Fe). Also, as shown in the previous section potassium acts as a promoter for the WGS reaction, and the state of iron is not the main factor which determines the WGS activity.

\section{Catalyst Deactivation and WGS reaction}

Iron FTS catalysts lose a part of their initial activity with time on stream due to several deactivation mechanisms: poisoning (mainly by sulphur in the feed), carbonaceous deposits, sintering and oxidation (i.e. conversion of iron carbides to magnetite) $[10,32,33]$. The latter two mechanisms are considered to be the most important for precipitated Fe catalysts used in low temperature Fischer-Tropsch synthesis $[32,33]$ and this is attributed to hydrothermal sintering and oxidation by water. Partial pressure of water depends on the extent of syngas conversion and the rate of WGS reaction. Experimental data showing variation of partial pressure with conversion for several Fe FTS catalysts are shown in Figures 5-7.

In our study with the Ruhrchemie catalyst partial pressure of water passed through a maximum at syngas conversion in $45-58 \%$ range, in tests with $\mathrm{H}_{2} / \mathrm{CO}$ molar feed of $0.67(\mathrm{~F}=$ 0.67), but no maximum was observed in tests with $\mathrm{F}=2$ for the range of conversions achieved (Fig. 5). The existence of a maximum is to be expected since water is a reaction intermediate in reactions (1) and (2). It is produced in the FTS reaction and consumed in the WGS reaction. Also, data show that partial pressure of water is higher with $\mathrm{F}=2$ than with $\mathrm{F}=0.67$ at a constant syngas conversion, which is consistent with the data in Fig. 3a showing that the extent of WGS reaction increases with decrease in $\mathrm{H}_{2} / \mathrm{CO}$ feed ratio. Data from studies at the Center for Applied Energy Research (University of Kentucky) [34, 35] show the same qualitative trends (Figs. 6 and 7). Partial pressure of water passes through a maximum as a function of contact time (reciprocal of space 
velocity) for both $F=0.67$ and $F=1.7$ (Fig. 6) or as a function of syngas conversion (Fig. 7). One can see that the maximum in partial pressure of water occurs at higher values of conversion for $\mathrm{F}$ $=1.7$ compared to $\mathrm{F}=0.67$, and that the water partial pressure at higher contact times (i.e. conversions) is significantly higher when $\mathrm{F}=1.7$ (Fig. 6). Figure 7 shows that partial pressure of water, at a constant conversion, is lower for the catalysts with higher potassium loading, which is consistent with potassium's role as promoter for the WGS reaction (Section 3.3). At high conversions the WGS is close to equilibrium and partial pressures of water are nearly the same regardless of $\mathrm{K}$ loading.

\section{Kinetics and Mechanism of WGS}

Since the WGS reaction has a significant influence on the partial pressure of FTS reactants, understanding its kinetics is very important. Several reviews of WGS kinetics have been published to date $[9,36]$ and proposed rate expressions are summarized in Table 3 . Some of the early kinetic studies focused on using empirical rate equations [37-39], the most popular one utilized a simple first order in $\mathrm{CO}[37,38]$. Even though they provided a reasonable fit of the experimental data, a

clear flaw was the lack of accounting for WGS reversibility [40]. Subsequent studies led to expressions that take into account reversibility, and utilize mechanistic approach rather than empirical power law type of expressions. The two WGS mechanisms most often used in derivation of kinetic expressions are the direct $\mathrm{CO}$ oxidation and the formate mechanism [41, 42].

Bohlbro and Mogensen [41] first developed a model based on a form of direct CO oxidation mechanism, where $\mathrm{CO}$ from the gas phase undergoes a reaction with adsorbed oxygen, formed by water decomposition with hydrogen release. This led to a complex expression with the nominator following mass action kinetics and denominator containing all of the species. 
The direct oxidation mechanism assumes that the catalyst surface is oxidized by water, producing $\mathrm{H}_{2}$, and then subsequently reduced by $\mathrm{CO}$, forming $\mathrm{CO}_{2}$ [40]. Based on experimental results with several supported iron catalyst, which showed limited change of oxidation state of iron cations, Rethwisch and Dumesic [42] dismissed the direct oxidation mechanism in favor of mechanism with formate species for the WGS reaction [36]. Since then, expressions based on variations of the formate mechanism have been used in several models of WGS kinetics $[36,40$, $43,44]$. The commonality between these models is that CO is adsorbed on the separate WGS active sites, where it reacts with adsorbed water or hydroxyl species forming the formate species. The latter step is typically considered to be the rate determining step. The dominant species on the WGS active surface are adsorbed water, hydroxyl and CO, meaning that the denominator contains partial pressures of water, $\mathrm{CO}$ and potentially $\mathrm{H}_{2}$. However, it is worth noting that models based of the formate mechanism were also not able to predict WGS behavior with high accuracy [40].

The exact mechanism of WGS over iron-based catalysts under low temperature FTS conditions is still far from being well understood. Krishnamoorthy et al. [45] performed an experimental analysis of WGS kinetics, in which both ${ }^{13} \mathrm{C}$-labeled and unlabeled $\mathrm{CO}_{2}$ were added to syngas. Their results showed that the $\mathrm{CO}_{2}$ formation occurs through two different pathways: primary - in which adsorbed oxygen reacts with adsorbed CO; secondary - in which adsorbed water reacts with CO-derived intermediates. Obviously, the primary pathway is reminiscent of previously mentioned direct $\mathrm{CO}$ oxidation mechanism for the WGS, while the secondary pathway corresponds to the formate mechanism. The presence of two parallel WGS reaction mechanisms, where the dominant mechanism would be dependent on catalyst composition and support, as well as the process conditions, could explain why so many studies arrived at different conclusions 
related to WGS kinetics and why none of the expressions could predict its behavior with high precision.

\section{WGS and Industrial Practice}

Sasol has been operating fixed bed reactors (Arge reactors) for low temperature FTS (LTFT) since mid 1950's. Over the years researchers from Sasol have presented information on various aspects of the LTFT process including product distribution, operating conditions, reaction kinetics and mechanism of FTS, catalyst composition and the overall process including upstream and downstream units in an integrated plant to produce fuels and chemicals from coal. Process conditions for the LTFT have been reported as: 493 - $513 \mathrm{~K}, 2$ - 2.8 MPa (4.5 MPa since 1987); $F=1.8-1.9[10,47,48]$. Arge reactors operate at relatively low single pass conversion and recycling of tail gas (after removal of water and heavy hydrocarbons) is utilized to achieve high overall conversion. However, values of conversion and recycle ratio (tail gas to fresh feed) have not been reported by Sasol's researchers for industrial reactors. Concerning conversion one can find the following information in Steynberg et al. [48]:'If the syngas feed is based on Lurgi gasifier product or natural gas reforming then the syngas $\mathrm{H}_{2} / \mathrm{CO}$ ratio will be at least 1.7. In this case water production is inevitable and the water partial pressure must be kept below 3 bar (300 kPa) in order to avoid catalyst deactivation by oxidation. For this reason per pass conversion is severely restricted and recycle and/or tandem operation is required to achieve reasonable overall conversion". This is consistent with results and discussion presented in Section 4.

The following information can be found in the open literature concerning conversion level and/or recycle ratio: Henrici-Olive [49] reported that operating conditions for Sasol's fixed bed reactors are: $493-513 \mathrm{~K}, 2-2.5 \mathrm{MPa}, \mathrm{H}_{2} / \mathrm{CO}=1.8$ and single pass conversion of $70 \%$ (referred to 
carbon). Brunner et al. [50] reported the following conditions for Arge reactors: $493 \mathrm{~K}, 2.7 \mathrm{MPa}$, $\mathrm{H}_{2} / \mathrm{CO}=1.8$, recycle/feed ratio $=2.2-2.5,60-66 \%$ single pass syngas conversion.

Due to the high cost of syngas production it is important to utilize the feed efficiently and thus the usage ratio should be close to the $\mathrm{H}_{2} / \mathrm{CO}$ feed ratio. Dry [11] states that for an iron catalyst operating at $498 \mathrm{~K}$ the usage ratio is 1.65 , which is somewhat lower than the feed ratio of 1.8 , but this is desirable since extra hydrogen is needed for downstream product upgrading. This is a relatively high usage ratio but the operation at low temperatures and high pressures favors higher usage ratios (see Sections 3.1 and 3.2). Based on our experiments with the Ruhrchemie catalyst (Figs. 2-4), which was used initially in Arge's reactors at Sasol, the single pass syngas conversions in the range 60-70\% as reported by Henrice-Olive [49] and Brunner et al. [50] are rather high for the usage ratio of 1.65 .

Another type of reactor and process for conversion of coal derived syngas to transportation fuels was developed by Rheinpreussen in mid 50's [51-53]. In this process FTS is conducted in a three-phase reactor (slurry bubble column reactor, SBCR) in which fine catalyst particles (30-90 $\mu \mathrm{m})$ are dispersed in a liquid medium (hydrocarbon wax) and the syngas is introduced into the reactor through a gas sparger. The $\mathrm{CO}$-rich syngas is fed to the reactor $(\mathrm{F}=0.5-0.67)$ and it is almost completely converted (syngas conversion of $\sim 90 \%$ ) in once through operation [53]. As shown earlier in this paper (Sections 2 and 3) it is possible to achieve high syngas conversions with $\mathrm{CO}$ rich syngas $(\mathrm{F} \sim 0.67)$ and to maintain low partial pressure of water due to high WGS reaction activity at operating conditions similar to those employed in Rheinpreussen's demonstration plant unit $(\mathrm{P}=1.2 \mathrm{MPa}, \mathrm{T}=541 \mathrm{~K}, \mathrm{~F}=0.67, \mathrm{SV}=3.1 \mathrm{NL} / \mathrm{g}-\mathrm{Fe} / \mathrm{h})$. Furthermore, the outlet $\mathrm{H}_{2} / \mathrm{CO}$ ratio at these high conversions is still low which minimizes $\mathrm{CH}_{4}$ selectivity and enhances selectivity to liquid products ( $\mathrm{C}_{5+}$ hydrocarbons). Since 1970's numerous studies on 
slurry reactors for low and medium temperature FTS have been conducted in both academia and industry, and a book edited by Steynberg and Dry [54] provides an excellent source of information on these developments.

Sasol was successful in solving problems encountered with catalyst/wax separation and a commercial size SBCR (5m ID, 22m high) with capacity of 2500 barrel/day of products was commissioned in 1993, and has successfully operated since then. This reactor was used for LTFT utilizing gas recycle to achieve high syngas feed conversion, i.e. it operated at similar conditions as the fixed bed Arge reactors. It has been mainly utilized for R\&D purposes, and it was essential for commercialization of GTL process which uses cobalt based FTS catalyst. Two slurry bubble column reactors (10m ID, 60m high) with capacity of 17000 barrels/day have been in operation in Qatar since 2006 (ORYX GTL), and a GTL plant of the same capacity has been commissioned in Nigeria in 2014.

Typical product distributions on Fe catalysts at Sasol's LTFT reactors [10, 47], Rheinpreussen's demonstration plant [51, 53], Mobil's pilot [55] and our laboratory [56] are shown in Table 4. Product distribution for a SBCR at Sasol [47] was given in terms of boiling point ranges for hydrocarbons above $\mathrm{C}_{7}$, and it would be difficult to map this accurately into carbon number ranges reported in the other studies. Methane selectivity in SBCR was higher than that in Sasol's fixed bed reactor probably due to the use of higher temperature in the former, but the liquid product selectivity $\left(\mathrm{C}_{5+}\right)$ was slightly higher in the SBCR (88\% vs $\left.86.3 \%\right)$. It should be noted that selectivities for Sasol reactors are reported on carbon atom basis, whereas those from other studies shown in Table 4 are on mass percent basis. This has no significant effect on results, and the maximum difference between these two bases is in $\mathrm{CH}_{4}$ selectivity, i.e. selectivity on carbon atom 
basis is approximately $10 \%$ less than that expressed on mass basis. With increase in molecular weight of hydrocarbon species the difference becomes negligible.

Rheinpreussen's demonstration plant data were obtained with $\mathrm{CO}$ rich feed gas at medium temperature of $538 \mathrm{~K}$, and a high single pass conversion was achieved. The plant operated in gasoline mode of production, and yield of $\left(\mathrm{C}_{5}-\mathrm{C}_{11}\right)$ hydrocarbons obtained is very high. This was accompanied by low yield of methane + ethane ( $3.2 \%$ only). This product distribution is very unusual and could not be reproduced in any other subsequent studies [48]. In all other studies (regardless of the reactor type) such low methane yields were accompanied by high yields of $\mathrm{C}_{12}+$ products, which is illustrated by data presented in Table 4. It should be noted that the reported total yield of hydrocarbons was only $178 \mathrm{~g} / \mathrm{Nm}^{3}$, which is indicative of problems with the product collection and/or analysis (theoretical stoichiometric yield is $208.5 \mathrm{~g} / \mathrm{Nm}^{3}$ of $\mathrm{H}_{2}+\mathrm{CO}$ converted). Steynberg et al. [48] believed that reported high conversions of CO and syngas are possible only with single pass conversions of 50-60\% and recycling of unconverted gas.

Mobil's product distribution in wax mode of operation is very similar to that in Sasol's fixed bed reactors, but was obtained under completely different process conditions (CO rich syngas and much higher reaction temperature) and at high single pass syngas conversion. Operating conditions were similar to those utilized in the Rheinpreussen's demonstration plant, but differences in product distribution between them were dramatic (except for similar $\mathrm{CH}_{4}$ selectivity).

Experiments conducted in a laboratory size STSR at Texas A\&M University (TAMU) were conducted under similar process conditions (T, P and feed composition) as those in Mobil's study and product distributions were similar. TAMU's catalyst produced more light gases $\left(\mathrm{CH}_{4}\right.$ and $\mathrm{C}_{2-}$ $\mathrm{C}_{4}$ ) but was significantly more active than the catalysts employed in Rheinpreussen's and Mobil's studies [56, 57]. Two sets of data are presented for TAMU's catalyst which illustrate the effect of 
increasing pressure and gas space velocity simultaneously to maintain the constant contact time in the reactor. Operation at higher pressure (2.2 MPa) resulted in a decrease in selectivity of $\mathrm{C}_{1}-\mathrm{C}_{4}$ hydrocarbons, and an increase of valuable $\mathrm{C}_{5+}$ products. At the same time the productivity increased by $\sim 50 \%$.

A significant portion of the costs associated with constructing and operating a CTL plant is related to the preparation of syngas, i.e. gasification of coal. There are three main types of gasifiers used for this purpose: 1) fixed-bed (e.g. Sasol-Lurgi gasifier); 2) fluidized-bed (e.g. Kellog-RustWestinghouse gasifier); and 3) entrained flow (Texaco and Shell gasifiers) [58, 59]. There are many differences between these gasifiers, but one of the primary ones is the composition of produced syngas. Sasol-Lurgi gasifier produces syngas with $\mathrm{H}_{2} / \mathrm{CO}$ ratio between 1.7 and 2.4, which is said to be optimal or close to optimal for Sasol's LTFT process. On the other hand, the entrained and fluid bed gasifier types produce a carbon-rich syngas. The entrained flow gasifiers produce syngas with $\mathrm{H}_{2} / \mathrm{CO}$ ratios of $0.4-0.9$, which depends on the coal quality. One of the key technical issues concerning the use of entrained flow gasifiers is the high temperature of raw syngas produced (above $1473 \mathrm{~K}$ ). However, if the heat from cooling of raw gas is used in the production of high pressure water steam, then the cold gas efficiency of Texaco and Shell gasifiers goes up to 95\% [58]. They are therefore highly competitive with Sasol-Lurgi process in terms of efficiency. In the 1980's and early 1990's, US Department of Energy funded a series of studies by the MITRE Corporation [60-63], which showed that, compared to the alternative technologies present at the time, the use of Shell gasifier with carbon-rich syngas in a slurry phase FTS reactors is the most economical approach. In other words, the selection of appropriate coal gasifier is influenced by desired syngas feed composition to the FTS reactor. 
Another concept for conducting FTS on industrial scale is based on the use of reactors in series (multistaging) with removal of water between stages. Water not only contributes to catalyst deactivation, but it also inhibits the rate of FTS $[9,10,15,64]$, and thus it is essential to keep the partial pressure of water at low values. Also, the reaction rate decreases as conversion increases, which is a drawback of the concept of high single pass conversion. When multiple stages are used, the conversion in the first reactor is relatively low $(\sim 50-60 \%)$, and the second reactor is used to achieve nearly complete conversion of the feed. This represents a trade-off between high operating costs associated with recycle operation and additional capital cost of the second reactor. This approach has been described in both patent and open literature [34, 65, 66]. Detailed process and economic evaluations are necessary to determine the most appropriate level of conversion and mode of operation (single stage or multistage) for Fe based catalysts for low and medium temperature FTS.

At the present time, commercialization of CTL technology is actively pursued in China [59]. Several commercial plants are planned to be commissioned in the near future and several are based on slurry phase medium temperature Fischer-Tropsch (MTFT) technology ( $\mathrm{T}=543-573 \mathrm{~K}$ ). Different types of coal gasifiers are being considered and the selection depends on the properties of coal feed. No information is provided on the syngas feed composition to FTS reactor, although it has been stated that "for most coal derived syngas, $\mathrm{H}_{2} / \mathrm{CO}$ ratio needs to be increased by using sulfur-resistance WGS unit". Also, there is no information on the conversion level in FTS reactors, except that Fig. 7 in Ref. [59] shows simplified flowsheet with tail gas recycle, which is according to Sasol's practice (low single pass conversion with gas recycle). It is claimed that the use of higher temperature $(548 \mathrm{~K})$ with the new catalyst resulted in significant increase in the hydrocarbon productivity relative to LTFT slurry phase process: from $0.25-0.3$ (LTFT) to $0.8-1.2 \mathrm{gC}_{3}+/ \mathrm{g}$-cat/h 
(MTFT), while decreasing $\mathrm{CH}_{4}$ selectivity from 5-10 wt $\%$ to $2.5-4 \mathrm{wt} \%$. The latter obviously does not reflect the effect of temperature, but is the consequence of using different catalysts for LTFT and MTFT.

\section{Conclusions}

WGS reaction plays an important role in CTL processes based on iron FT catalysts. The extent of WGS reaction determines concentrations of reactants and water, and this in turn has significant impact on product distribution and catalyst deactivation. High partial pressure of water is a major cause of deactivation (oxidation of active carbide phase). In addition, water inhibits the rate of FTS. The usage ratio is strongly affected by syngas feed ratio and total syngas conversion. As the syngas conversion increases the exit $\mathrm{H}_{2} / \mathrm{CO}$ ratio also increases and is much higher than the feed ratio particularly for $\mathrm{H}_{2} / \mathrm{CO}$ feed ratios greater than 1 . High $\mathrm{H}_{2} / \mathrm{CO}$ ratio in the reactor favors chain termination reactions and results in unfavorable selectivity (high amount of $\mathrm{CH}_{4}$ and low molecular weight hydrocarbons). The WGS activity increases with increase in temperature, decrease in pressure and is a function of catalyst composition (e.g. K loading) and activation conditions.

Reactors for FTS with $\mathrm{H}_{2} / \mathrm{CO}$ feed ratios of $1.7-2.2$ operate at low single pass conversions to avoid high partial pressure of water, and efficient utilization of the feed is achieved using gas recycle. If the $\mathrm{CO}$ rich syngas is used as the feed the usage and the exit ratios do not vary significantly with conversion, and high syngas conversions can be achieved in once through operation. A few examples of industrial practice and proposed reactor designs have been presented. 


\section{Acknowledgements}

This work was supported in part by US DOE grant DE-FG26-02NT41540 and Qatar Foundation. 


\section{References}

[1] H. Schulz, Appl. Catal.,A, 186 (1999) 3.

[2] F.G. Botes, J.W. Niemantsverdriet and J. van de Loosdrecht, Catal. Today, 215 (2013)

112.

[3] B.H. Davis, Ind. Eng. Chem. Res., 46 (2007) 8938.

[4] C.N. Satterfield and G.A. Huff, Jr., Can. J. Chem. Eng., 60 (1982) 159.

[5] D.B. Bukur and R.F. Brown, Can. J. Chem. Eng., 65 (1987) 604.

[6] D.S. Newsome, Catal. Rev. - Sci. Eng., 21 (1980) 275.

[7] R.F. Brown, Fischer-Tropsch synthesis in the slurry phase on iron catalysts, MSc Thesis, Texas A\&M University, 1986.

[8] D.B. Bukur, Kinetics of slurry phase Fischer-Tropsch synthesis, DOE Final Report for Grant No. DE-FG26-02NT41540,2006.

[9] W.H. Zimmerman and D.B. Bukur, Can. J. Chem. Eng., 68 (1990) 292.

[10] Dry, M. E. The Fischer-Tropsch Synthesis. in Catalysis-Science and Technology;

Anderson, J. R., Boudart, M., Eds.; Springer-Verlag: New York, 1981; Vol. 1, pp. 160-255.

[11] M.E. Dry, in A.P. Steynberg and M.E. Dry (Editors), Stud. Surf. Sci. Catal., 152 (2004), 196.

[12] B. Todic, N. Nikacevic and D.B. Bukur, submitted to Cat. Today, (2015).

[13] T.J. Donnely, Product distributions of the Fischer-Tropsch synthesis, PhD Thesis, Massachusetts Institute of Technology, 1989.

[14] N.S. Govender, M.J. Van Vuuren, M. Claeys and E. van Steen, Ind. Eng. Chem. Res., 45 (2006) 8629.

[15] R.B. Anderson, .Catalysts for the Fischer-Tropsch Synthesis, in Catalysis; Emmett, P. H., Ed.; Van Nostrand-Reinhold: New York 1956; Vol. IV, pp. 29-255.

[16] M.E. Dry and G.J. Oosthuizen, J. Catal., 11 (1968) 18.

[17] R.B. Anderson, B. Seligman, J.F. Shultz, R. Kelly and M.A. Elliott, Ind. Eng. Chem., 44 (1952) 391.

[18] J.F. Shultz, L.J. E. Hofer, E.M. Cohn, K. C. Stein and R.B. Anderson, Synthetic liquid fuels from hydrogenation of carbon monoxide, U. S. Bureau of Mines, Bulletin 578 (1959).

[19] H. Arakawa and A.T. Bell, Ind. Eng. Chem. Process Des. Dev., 22 (1983) 97.

[20] D.B. Bukur, D. Mukesh and S.A. Patel, Ind. Eng. Chem. Res., 29 (1990) 194.

[21] A.P. Raje, R.J. O'Brien and B.H. Davis, J. Catal., 180 (1998) 36.

[22] N. Lohitharn and J.G. Goodwin, J. Catal., 260 (2008) 7.

[23] W. Ma, G. Jacobs, U.M. Graham and B.H. Davis, Top. Catal., 57 (2014) 561.

[24] W. Ma, E.L. Kugler and D.B. Dadyburjor, Energy Fuels, 21 (2007) 1832.

[25] Y. Yang, H.-W. Xiang, Y.-Y. Xu, L. Bai and Y.-W. Li, Appl. Catal., A, 266 (2004) 181.

[26] C.H. Bartholomew and R.J. Farrauto, Fundamentals of Industrial Catalytic Processes, John Wiley \& Sons, New Jersey, 2006.

[27] G. Jacobs and B.H. Davis, Appl. Catal., A, 333 (2007) 192.

[28] D.B. Bukur, X. Lang, J.A. Rossin, W.H. Zimmerman, M.P. Rosynek, E.B. Yeh and C. Li, Ind. Eng. Chem. Res., 28 (1989) 1130.

[29] D.B. Bukur, M. Koranne, X. Lang, K.R.P.M. Rao and G.P. Huffman, Appl. Catal., A, 126 (1995) 85.

[30] D.B. Bukur, Z. Nowicki, R.K. Manne and X. Lang, J. Catal., 155 (1995) 366.

[31] D.B. Bukur, L. Nowicki and X. Lang, Energy Fuels, 9 (1995) 620. 
[32] B. Jager and R. Espinoza, Catal. Today, 23 (1995) 17.

[33] D.J. Duvenhage and N.J. Coville, Appl. Catal., A, 298 (2006) 211.

[34] A.P. Raje and B.H. Davis, Catal. Today, 36 (1997) 335.

[35] B.H. Davis, Catal. Today, 84 (2003) 83.

[36] G.P. van der Laan and A.A.C.M. Beenackers, Appl. Catal., A, 193 (2000) 39.

[37] M.E. Dry, Ind. Eng. Chem., Prod. Res. Dev., 15 (1976) 282.

[38] J.L. Feimer, P.L. Silveston and R.R. Hudgins, Ind. Eng. Chem. Prod. Res. Dev., 20 (1981) 609.

[39] G. Bub and M. Baerns, Chem. Eng. Sci., 35 (1980) 348.

[40] F.G. Botes, Appl. Catal., A, 328 (2007) 237.

[41] H. Bohlbro and E. Mogensen, An investigation on the kinetics of the conversion of carbon monoxide with water vapour over iron oxide based catalysts, Gjellerup, København, 1969.

[42] D.G. Rethwisch and J.A. Dumesic, J. Catal., 101 (1986) 35.

[43] E.S. Lox and G.F. Froment, Ind. Eng. Chem. Res., 32 (1993) 71.

[44] B.-T. Teng, J. Chang, J. Yang, G. Wang, C.-H. Zhang, Y.-Y. Xu, H.-W. Xiang and Y.-W. Li, Fuel, 84 (2005) 917.

[45] S. Krishnamoorthy, A. Li and E. Iglesia, Catal. Lett., 80 (2002) 77.

[46] W.-J. Shen, J.-L. Zhou and B.-J. Zhang, J. Nat. Gas Chem., 3 (1994) 385.

[47] M.E. Dry, Appl. Catal., A, 189 (1999) 185.

[48] A.P. Steynberg, M.E. Dry, B.H. Davis and B.B. Breman, in A.P. Steynberg and M.E. Dry (Editors), Stud. Surf. Sci. Catal., 152 (2004), 64.

[49] G. Henrici-Olive and S. Olive, Angew. Chem., 88 (1976) 144.

[50] K.M. Brunner, J.C. Duncan, L.D. Harrison, K.E. Pratt, R.P.S. Peguin, C.H. Bartholomew and W.C. Hecker, Int. J. Chem. React. Eng., 10 (2012) Article A13.

[51] H. Kölbel, P. Ackerman and F. Engelhardt, New Developments in Hydrocarbon Synthesis, in Proc. Fourth World Petroleum Congress, Section IV/C, Carlo Colombo Publishers, Rome 1955, pp. 227-247.

[52] H. Kölbel and P. Ackermann, Chem. Ing. Tech., 28 (1956) 381.

[53] H. Kölbel and M. Ralek, Catal. Rev. - Sci. Eng., 21 (1980) 225.

[54] M.E. Dry and A.P. Steynberg (Editors), Fischer-Tropsch Technology, Stud. Surf. Sci. Catal., 152 (2004).

[55] J.C.W. Kuo, Two-stage process for conversion of synthesis gas to high quality transportation fuels, DOE Final Report for Contract No. DE-AC22-83PC600019, 1985.

[56] D.B. Bukur and X. Lang, Ind. Eng. Chem. Res., 38 (1999) 3270.

[57] D.B. Bukur, L. Nowicki and X. Lang, Chem. Eng. Sci., 49 (1994) 4615.

[58] K. Aasberg-Petersen, T.S. Christensen, I. Dybkjaer, J. Sehested, M. Østberg, R.M. Coertzen, M.J. Keyser and A.P. Steynberg, in A.P. Steynberg and M.E. Dry (Editors), Stud. Surf. Sci. Catal., 152 (2004), 258.

[59] J. Xu, Y. Yang and Y.-W. Li, Fuel, 152 (2015) 122.

[60] D. Gray, M. Lytton, M. Neuworth and G. Tomlinson, Impact of developing technology on indirect liquefaction, DOE Final Report for Contract No. EF-77CO1-2738, 1980.

[61] D. Gray and G.C. Tomlinson, Assessing the economic impact of indirect liquefaction process improvements: Volume 1, DOE Final Report for Contract No. SAND-89-7089, 1990.

[62] D. Gray and G. Tomlinson, in M. De Pontes, R.L. Espinoza, C.P. Nicolaides, J.H.

Scholtz and M.S. Scurrell (Editors), Stud. Surf. Sci. Catal., 107 (1997), 145. 
[63] J. Neathery, D. Gray, D. Challman and F. Derbyshire, Fuel, 78 (1999) 815.

[64] G.A. Huff and C.N. Satterfield, Ind. Eng. Chem. Proc. Des. Dev., 23 (1984) 696.

[65] K. Agee and R. Espinoza, Fischer-Tropsch hydrocarbon synthesis process, Syntroleum Corporation, US Patent 2007/0259973, 2007.

[66] A. Raje, J.R. Inga and B.H. Davis, Fuel, 76 (1997) 273. 


\section{List of Tables:}

Table 1. Effect of temperature and pressure on usage ratio over fused and Ruhrchemie iron catalysts.

Table 2. Effect of catalyst activation procedure on WGS reaction.

Table 3. Summary of WGS kinetic rate expressions for iron-based FT catalysts.

Table 4. Product distribution in fixed bed and slurry phase reactors for FTS.

\section{List of Figures:}

Figure 1. Effect of syngas conversion level and feed $\mathrm{H}_{2} / \mathrm{CO}$ ratios on: a) usage ratios; b) exit $\mathrm{H}_{2} / \mathrm{CO}$ ratios; with fused iron catalyst in a stirred tank slurry reactor (Data from Brown (1986) [7]. Catalyst: C73-1-01 from United Catalyst Inc., with composition 2-3\% $\mathrm{Al}_{2} \mathrm{O}_{3}, 0.5-0.8 \% \mathrm{~K}_{2} \mathrm{O}$, 0.7$1.2 \% \mathrm{CaO}$ and $<0.4 \% \mathrm{SiO}_{2}$ mass basis).

Figure 2. Effect of syngas conversion and feed $\mathrm{H}_{2} / \mathrm{CO}$ ratios on: a) usage ratios; b) exit $\mathrm{H}_{2} / \mathrm{CO}$ ratios; with precipitated iron catalyst in a stirred tank slurry reactor (Data from Bukur (2006) [8] and Zimmerman and Bukur (1990) [9]. Catalyst: LP 33/81 obtained from Ruhrchemie AG with composition $100 \mathrm{Fe} / 5 \mathrm{Cu} / 4.2 \mathrm{~K} / 25 \mathrm{SO}_{2}$ mass basis).

Figure 3. Effect of temperature on the usage ratio over a precipitated iron catalyst in a stirred tank slurry reactor for: a) feed $\mathrm{H}_{2} / \mathrm{CO}$ ratio of $0.67(\mathrm{P}=1.5 \mathrm{MPa})$; b) feed $\mathrm{H}_{2} / \mathrm{CO}$ ratio of $2.0(\mathrm{P}=1.5$ MPa); (Data from Bukur (2006) [8]. Catalyst: LP 33/81 from Ruhrchemie).

Figure 4. Effect of pressure on the usage ratio over precipitated iron catalyst in a stirred tank slurry reactor for: a) feed $\mathrm{H}_{2} / \mathrm{CO}$ ratio of $0.67(\mathrm{~T}=533 \mathrm{~K})$; b) feed $\mathrm{H}_{2} / \mathrm{CO}$ ratio of $2.0(\mathrm{~T}=533 \mathrm{~K})$; (Data from Bukur (2006) [8]. Catalyst: LP 33/81 from Ruhrchemie).

Figure 5. Effect of process conditions on the water partial pressure (Data from Bukur (2006) [8] and Zimmerman and Bukur (1990) [9]. Catalyst: LP 33/81 from Ruhrchemie). 
Figure 6. Partial pressure of water as a function of space time for two different feed ratios (open symbols: $\mathrm{F}=1.7$; closed symbols: $\mathrm{F}=0.67$ ). Precipitated iron catalyst (weight composition $61.8 \%$ $\mathrm{Fe}, 0.897 \% \mathrm{Si}, 0.311 \% \mathrm{~K}$ and balance oxygen) in a stirred tank slurry reactor at $\mathrm{T}=543 \mathrm{~K}$ and $\mathrm{P}$ = 1.3 MPa. (Adapted from A.P. Raje and B.H. Davis, Catal. Today, 36 (1997) 335. [34] with permission from Elsevier).

Figure 7. Water partial pressure as a function of conversion for catalysts with different K contents. Catalyst: $100 \mathrm{Fe} / 4.6 \mathrm{Si} / 0.36-2.2 \mathrm{~K}$ atomic basis; Stirred tank slurry reactor at $\mathrm{T}=543$ $\mathrm{K}, \mathrm{P}=1.3 \mathrm{MPa}, \mathrm{H}_{2} / \mathrm{CO}=$ 0.67). (Modified from B.H. Davis, Catal. Today, 84 (2003) 83. [35] with permission from Elsevier). 
Table 1.

\begin{tabular}{|l|c|c|c|c|c|c|c|}
\hline Catalyst & $\begin{array}{c}\text { Effect of process } \\
\text { conditions }\end{array}$ & $\begin{array}{c}\mathbf{T} \\
(\mathbf{K})\end{array}$ & $\begin{array}{c}\mathbf{P} \\
(\mathbf{M P a})\end{array}$ & $\begin{array}{c}\mathbf{F} \\
\mathbf{( - )}\end{array}$ & $\begin{array}{c}\mathbf{X}_{\mathbf{H} 2+\mathbf{C O}} \\
\mathbf{( \% )}\end{array}$ & $\begin{array}{c}\mathbf{U} \\
\mathbf{( - )}\end{array}$ & Reference \\
\hline Fused & Effect of T & 523 & 1.41 & 0.68 & 42 & 0.74 & \\
& & 538 & 1.34 & 0.68 & 49 & 0.68 & {$[7]$} \\
& \multirow{2}{*}{ Effect of P } & 538 & 1.31 & 1.81 & 60 & 0.94 & \\
& & 538 & 2.72 & 1.81 & 59 & 0.86 & \\
\hline Ruhrchemie & Effect of T & 505 & 2.67 & 0.73 & 26 & 1.34 & \\
& & 521 & 2.72 & 0.70 & 28 & 1.06 & \\
& & 521 & 2.72 & 0.73 & 35 & 1.06 & \\
& & 536 & 2.72 & 0.73 & 34 & 0.99 & {$[13]$} \\
& \multirow{2}{*}{ Effect of P } & 521 & 2.20 & 0.76 & 26 & 1.39 & \\
& & 521 & 3.03 & 0.73 & 30 & 1.11 & \\
\hline
\end{tabular}


Table 2 .

\begin{tabular}{|c|l|l|l|l|r|}
\hline Catalyst & Activation & $\begin{array}{l}\mathrm{X}_{\mathrm{H} 2+\mathrm{CO}} \\
(\%)\end{array}$ & $\begin{array}{l}\mathrm{U} \\
(-)\end{array}$ & $\begin{array}{l}\text { PQwGS } \\
(-)\end{array}$ & Reference \\
\hline \multirow{3}{*}{$100 \mathrm{Fe} / 5 \mathrm{Cu} / 4.2 \mathrm{~K} / 25 \mathrm{SiO}_{2}$} & $\mathrm{H}_{2}, 553 \mathrm{~K}, 1 \mathrm{~h}$ & 60.5 & 0.65 & 9.9 & [30] \\
\cline { 2 - 5 } & $\mathrm{CO}, 553 \mathrm{~K}, 12 \mathrm{~h}$ & 58.6 & 0.76 & 2.2 & \\
\hline \multirow{3}{*}{$100 \mathrm{Fe} / 5 \mathrm{Cu} / 4.2 \mathrm{~K} / 16 \mathrm{SiO}_{2}$} & $\mathrm{H}_{2}, 513 \mathrm{~K}, 2 \mathrm{~h}$ & $78-81$ & $0.58-0.59$ & $20-37$ & [31] \\
\cline { 2 - 5 } & $\mathrm{CO}, 553 \mathrm{~K}, 8 \mathrm{~h}$ & $76-78$ & 0.59 & $9-12$ & \\
\hline \multirow{2}{*}{$100 \mathrm{Fe} / 0.3 \mathrm{Cu} / 0.8 \mathrm{~K}$} & $\mathrm{H}_{2}, 523 \mathrm{~K}, 2 \mathrm{~h}$ & 81.4 & 0.61 & 70.7 & [29] \\
\cline { 2 - 5 } & $\begin{array}{l}\mathrm{H}_{2} / \mathrm{CO}=0.67, \\
553 \mathrm{~K}, 8 \mathrm{~h}\end{array}$ & 70.7 & 0.64 & 20 & \\
\hline
\end{tabular}

Process conditions: $1.48 \mathrm{MPa}, \mathrm{H}_{2} / \mathrm{CO}=0.67 ; 523 \mathrm{~K}[29,30], 533 \mathrm{~K}$ [31] 
Table 3.

\begin{tabular}{|c|c|c|}
\hline Rate equation & $\mathrm{E}_{\mathrm{a}}(\mathrm{kJ} / \mathrm{mol})$ & Ref. \\
\hline$R_{W G S}=k_{W G S} P_{C O}$ & 124 & {$[9,37,38]$} \\
\hline$R_{W G S}=k_{W G S} \frac{P_{C O} P_{\mathrm{H}_{2} \mathrm{O}}-P_{\mathrm{CO}_{2}} P_{\mathrm{H}_{2}} / K_{W G S}}{P_{\mathrm{CO}}+a \cdot P_{\mathrm{H}_{2} \mathrm{O}}+b \cdot P_{\mathrm{CO}_{2}}+c \cdot P_{\mathrm{H}_{2}}}$ & - & [41] \\
\hline$R_{W G S}=k_{W G S}\left(P_{C O} P_{H_{2} O}-P_{C_{2}} P_{H_{2}} / K_{W G S}\right)$ & & [9] \\
\hline$R_{W G S}=k_{W G S} \frac{P_{C O} P_{\mathrm{H}_{2} \mathrm{O}}-P_{\mathrm{CO}_{2}} P_{\mathrm{H}_{2}} / K_{W G S}}{P_{\mathrm{CO}}+a \cdot P_{\mathrm{H}_{2} \mathrm{O}}+b \cdot P_{\mathrm{CO}_{2}}}$ & 125 & {$[9,46]$} \\
\hline$R_{W G S}=k_{W G S} \frac{P_{C O} P_{\mathrm{H}_{2} \mathrm{O}}-P_{\mathrm{CO}_{2}} P_{\mathrm{H}_{2}} / K_{W G S}}{P_{\mathrm{H}_{2}} P_{C O}+a \cdot P_{\mathrm{H}_{2} \mathrm{O}}}$ & 88 & {$[9,46]$} \\
\hline$R_{W G S}=k_{W G S} \frac{P_{C O} P_{\mathrm{H}_{2} \mathrm{O}}-P_{\mathrm{CO}_{2}} P_{\mathrm{H}_{2}}^{1 / 2} / K_{W G S}}{\left(1+a \cdot P_{\mathrm{H}_{2} \mathrm{O}} / P_{\mathrm{H}_{2}}^{1 / 2}\right)^{2}}$ & 27.7 & {$[43]$} \\
\hline$R_{W G S}=k_{W G S} \frac{P_{C O} P_{\mathrm{H}_{2} \mathrm{O}}-P_{\mathrm{CO}_{2}} P_{\mathrm{H}_{2}} / K_{W G S}}{\left(1+a \cdot P_{C O}+b \cdot P_{\mathrm{H}_{2} \mathrm{O}}\right)^{2}}$ & - & {$[36]$} \\
\hline$R_{W G S}=k_{W G S} \frac{P_{C O} P_{\mathrm{H}_{2} \mathrm{O}} / P_{\mathrm{H}_{2}}^{1 / 2}-P_{\mathrm{CO}_{2}} P_{\mathrm{H}_{2}}^{1 / 2} / K_{W G S}}{\left(1+a \cdot P_{C O}+b \cdot P_{\mathrm{H}_{2} \mathrm{O}}\right)^{2}}$ & - & {$[36]$} \\
\hline$R_{W G S}=k_{W G S} \frac{P_{C O} P_{\mathrm{H}_{2} \mathrm{O}}-P_{\mathrm{CO}_{2}} P_{\mathrm{H}_{2}} / K_{W G S}}{\left(1+a \cdot P_{\mathrm{H}_{2} \mathrm{O}}+b \cdot P_{\mathrm{H}_{2} \mathrm{O}} / P_{\mathrm{H}_{2}}^{1 / 2}\right)^{2}}$ & - & [40] \\
\hline
\end{tabular}


Table 4.

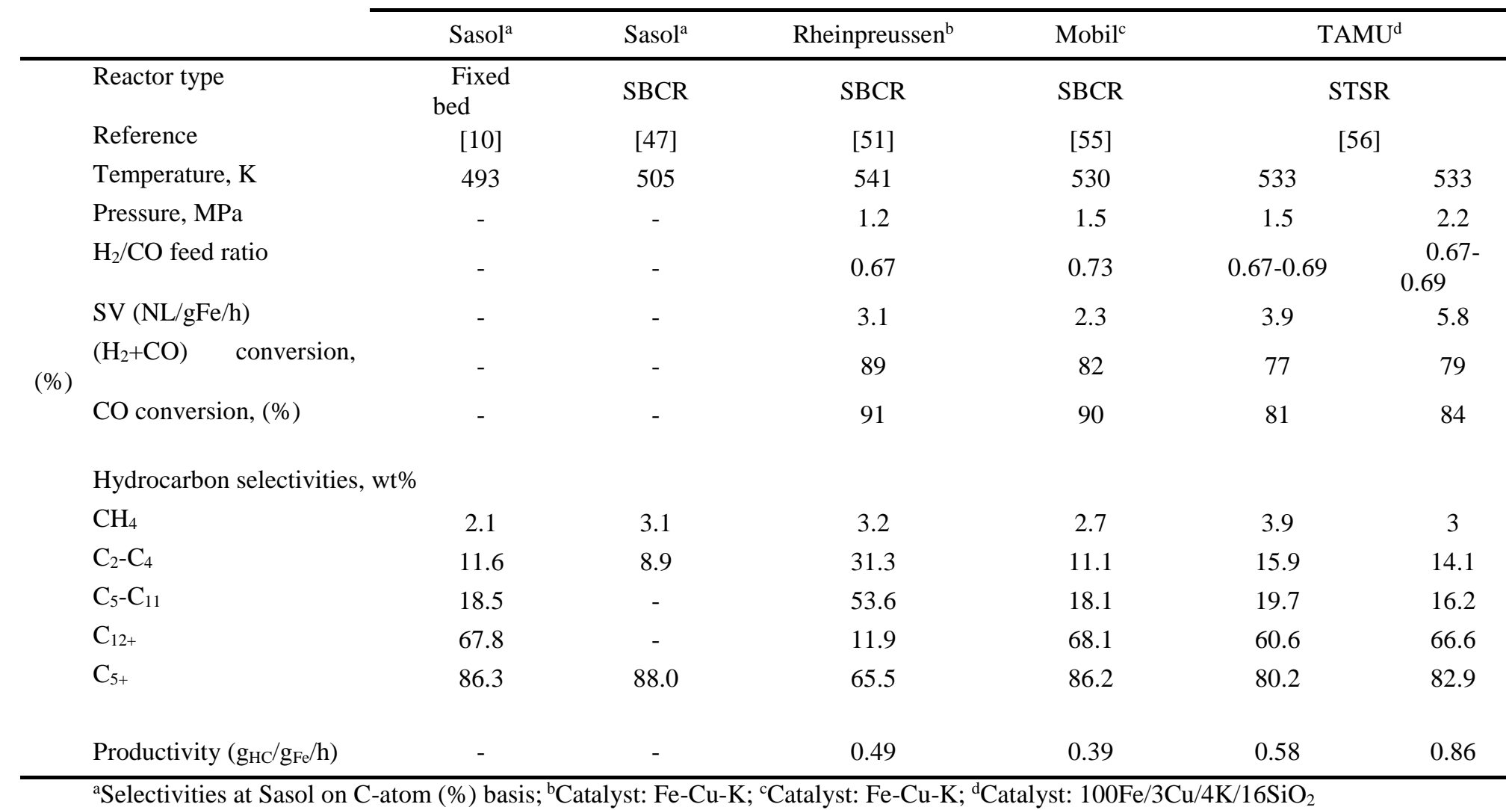

${ }^{a}$ Selectivities at Sasol on C-atom (\%) basis; ${ }^{b} \mathrm{Catalyst}$ : $\mathrm{Fe}-\mathrm{Cu}-\mathrm{K} ;{ }^{\mathrm{c} C a t a l y s t: ~} \mathrm{Fe}-\mathrm{Cu}-\mathrm{K} ;{ }^{\mathrm{d} C a t a l y s t: ~} 100 \mathrm{Fe} / 3 \mathrm{Cu} / 4 \mathrm{~K} / 16 \mathrm{SiO}{ }_{2}$ 
Figure 1a

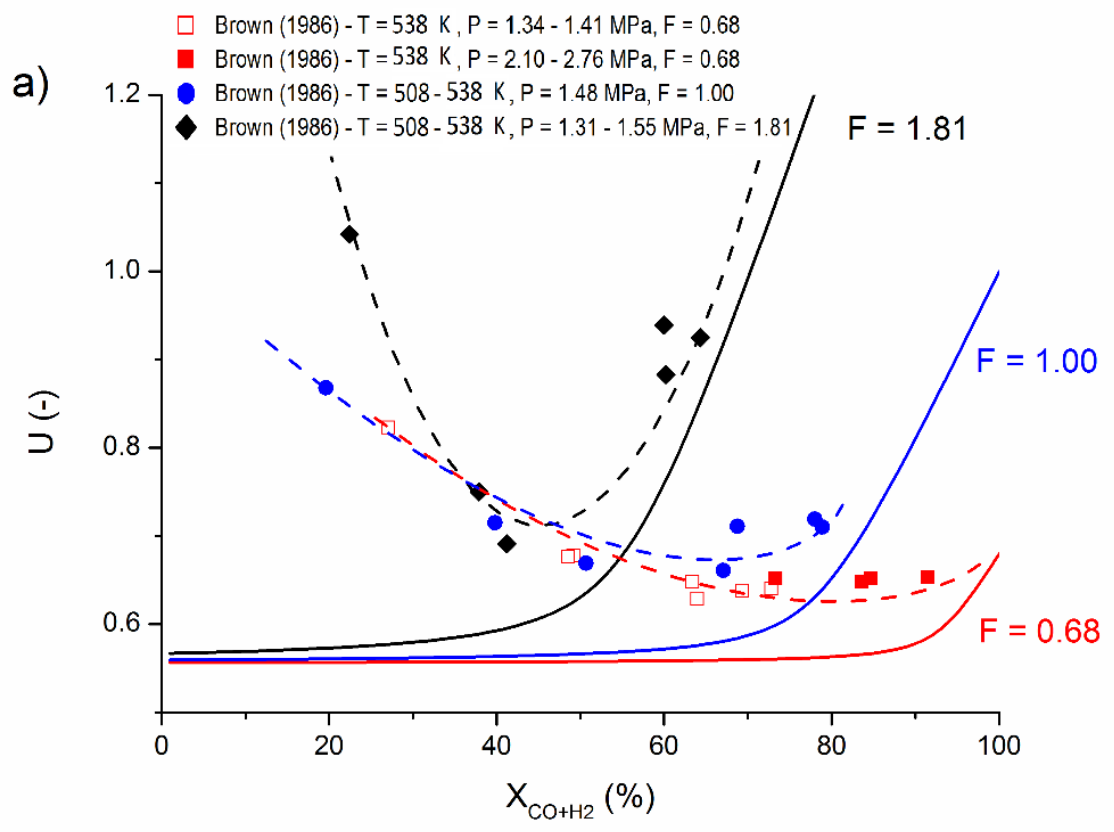

Figure 1b

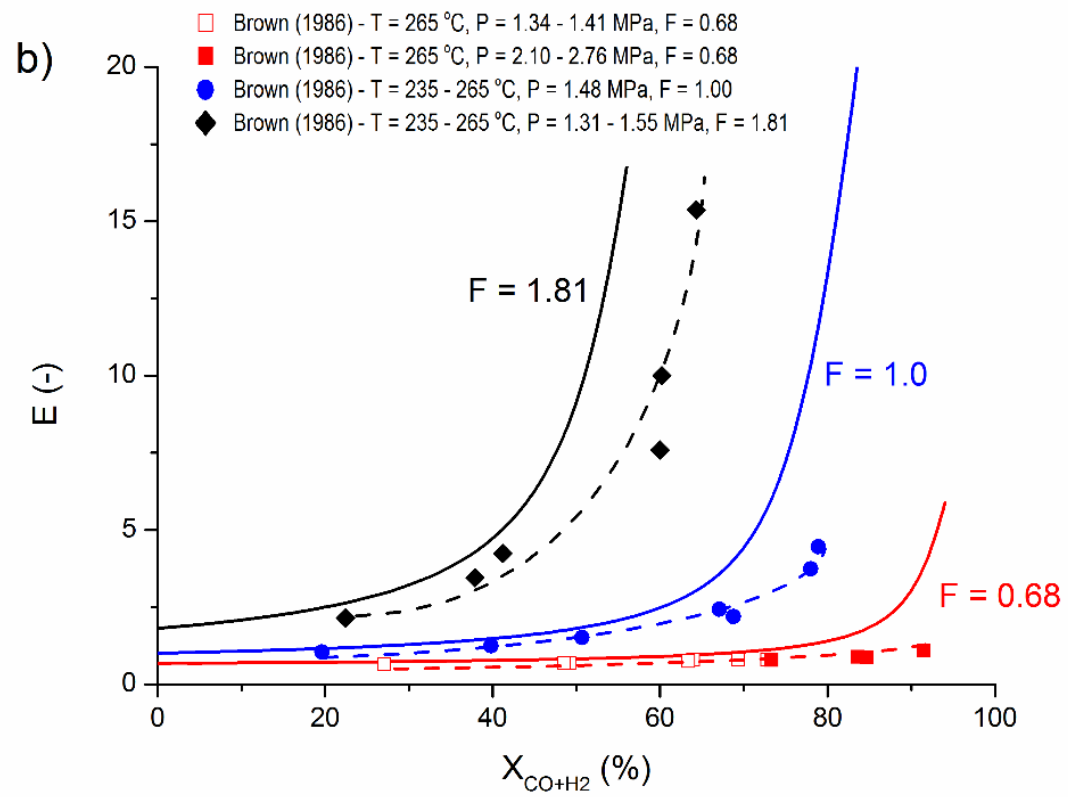


Figure 2a

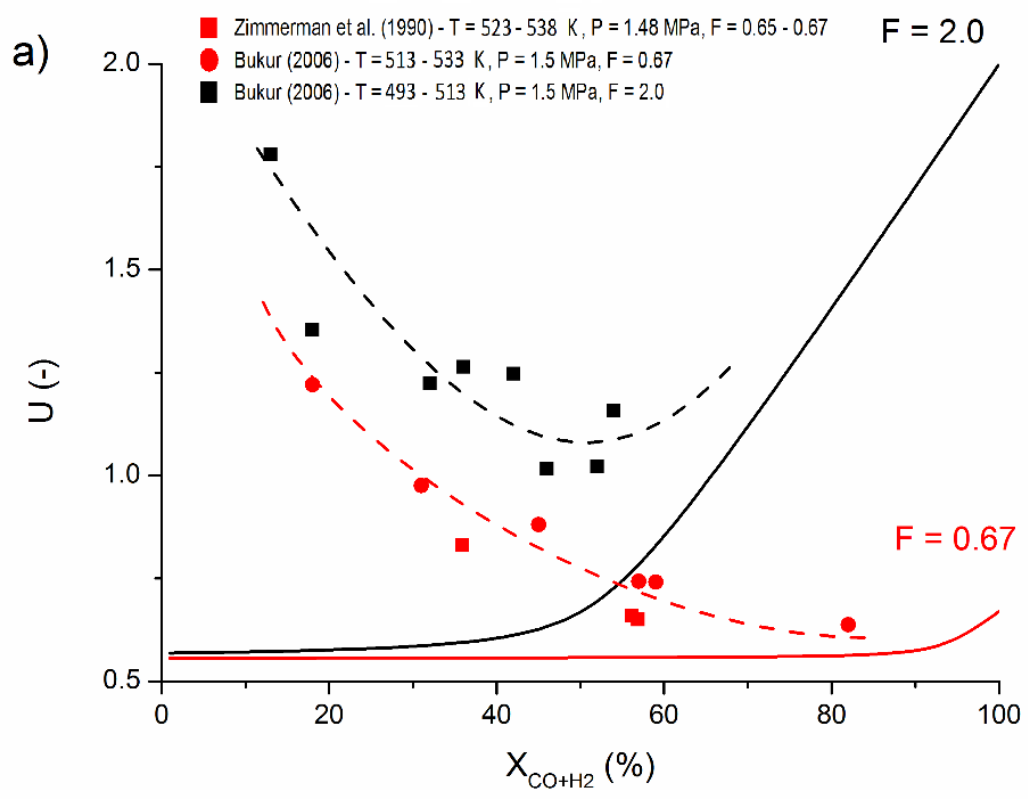

Figure $2 b$

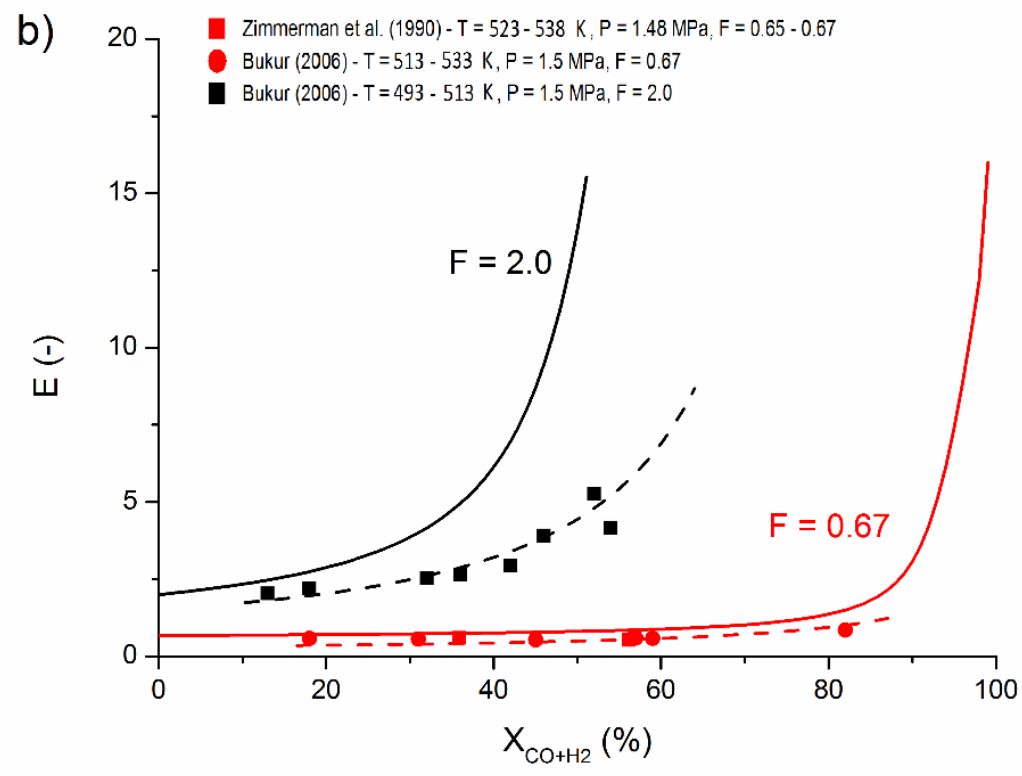


Figure 3a

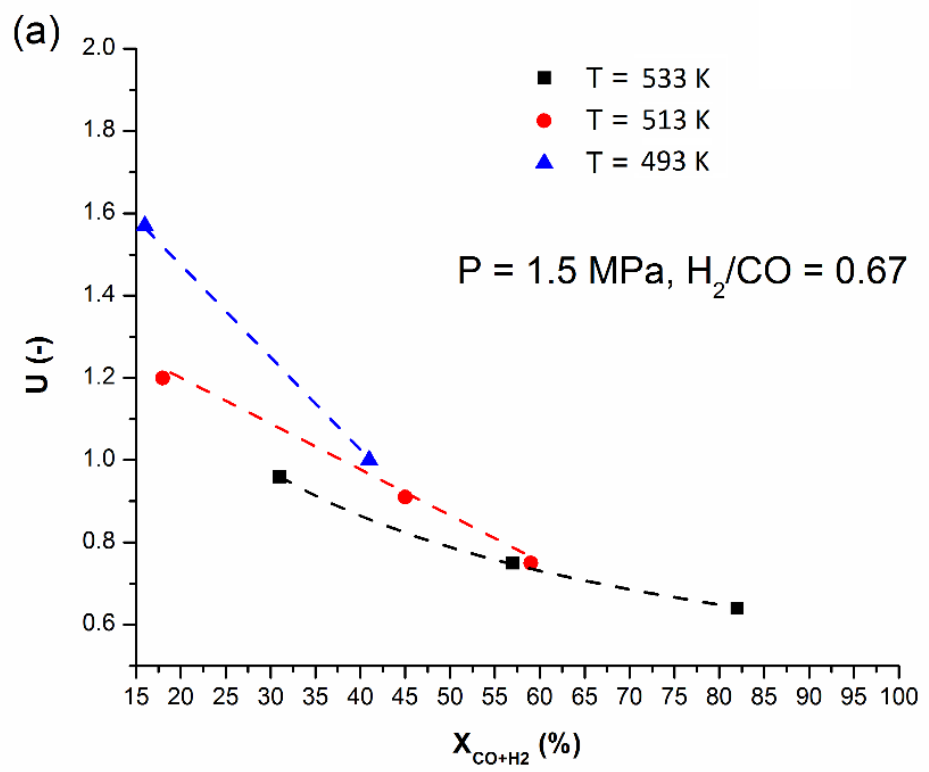

Figure $3 b$

(b)

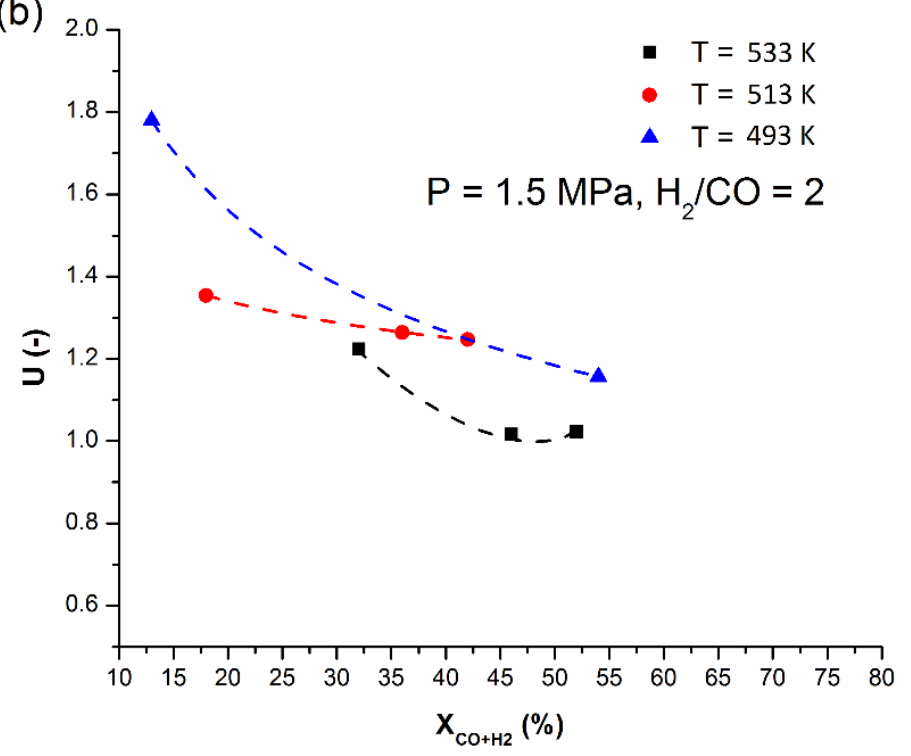


Figure 4a

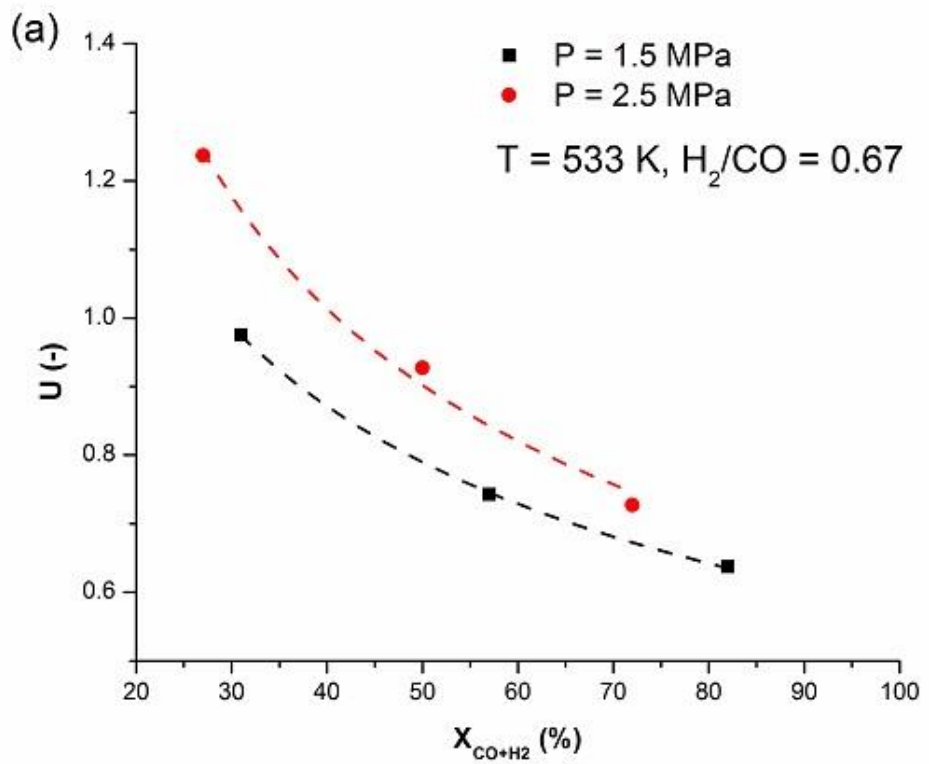

Figure $4 b$

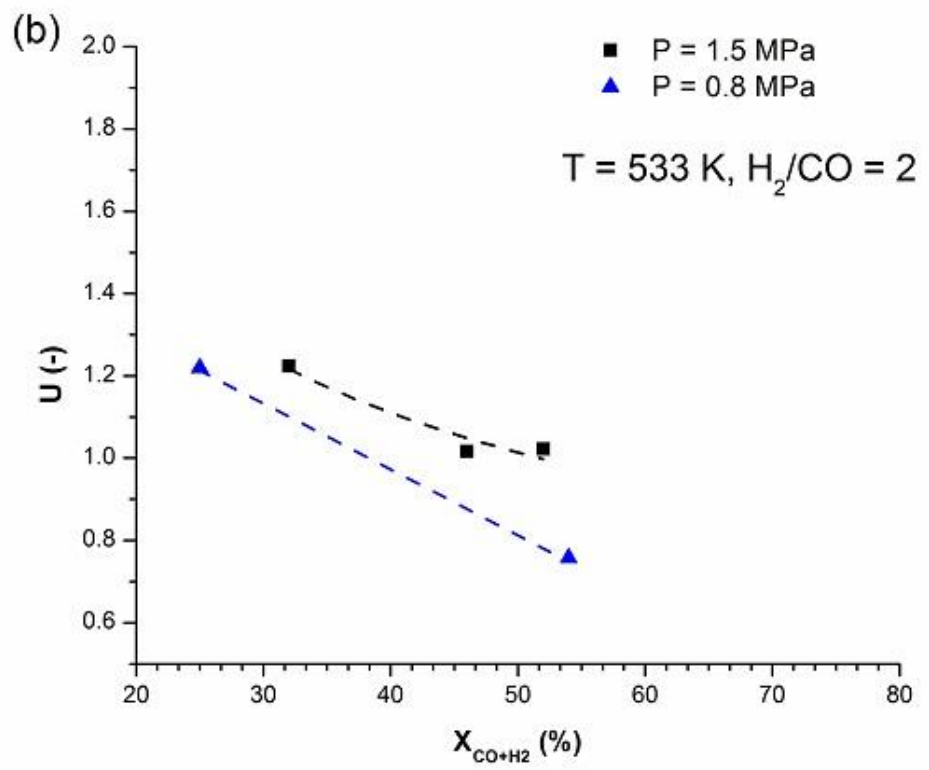


Figure 5

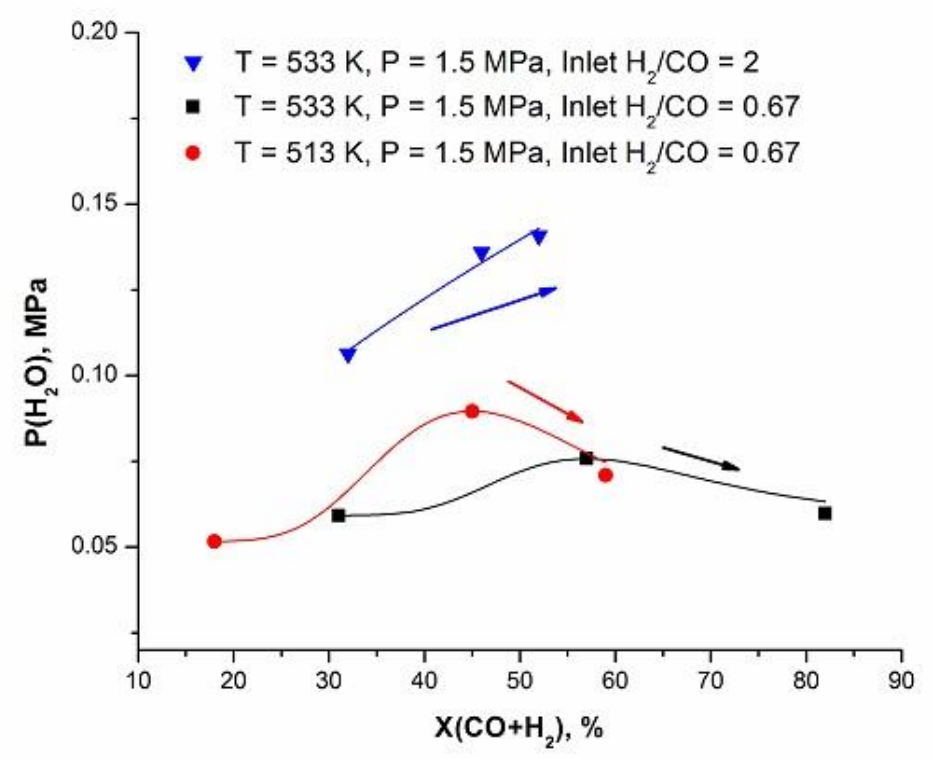


Figure 6

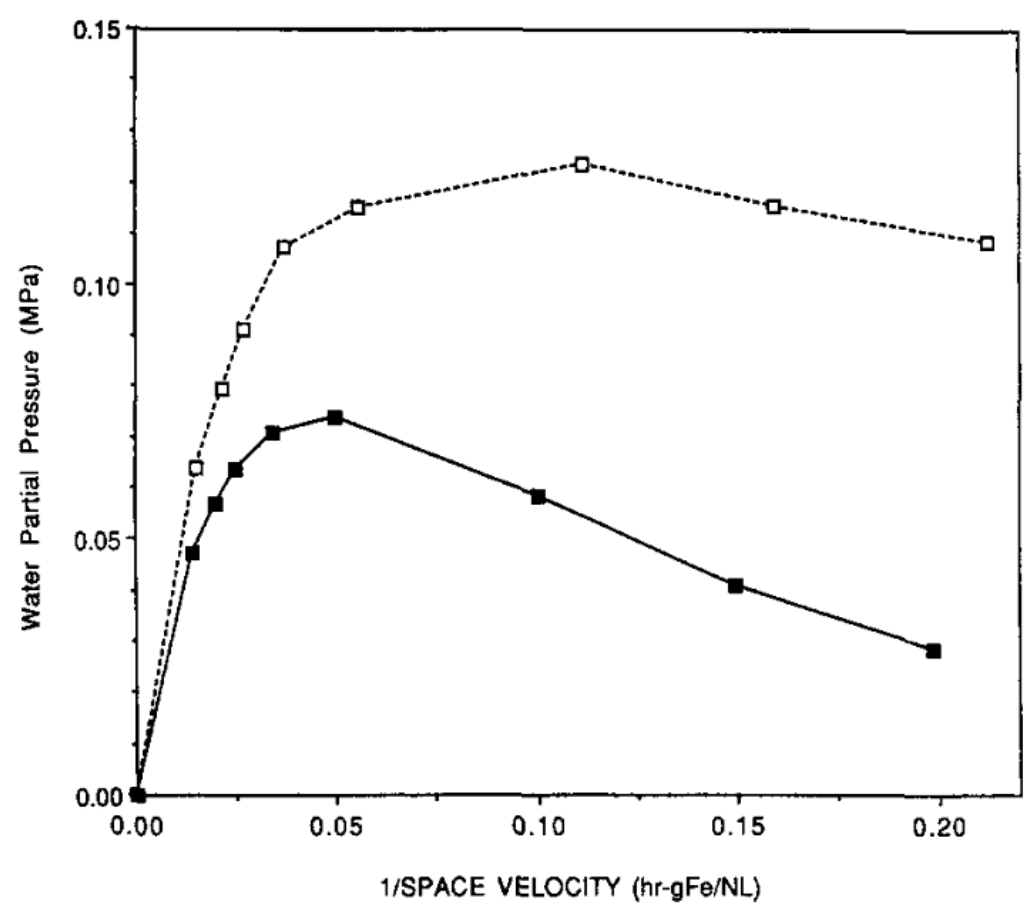

Figure 7

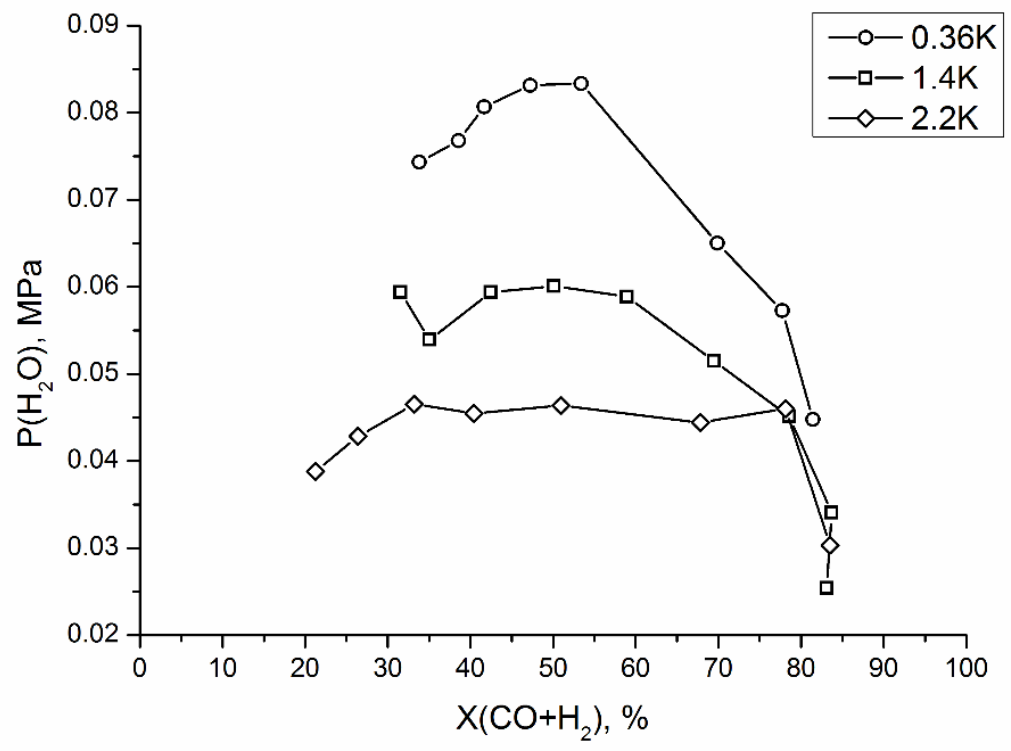




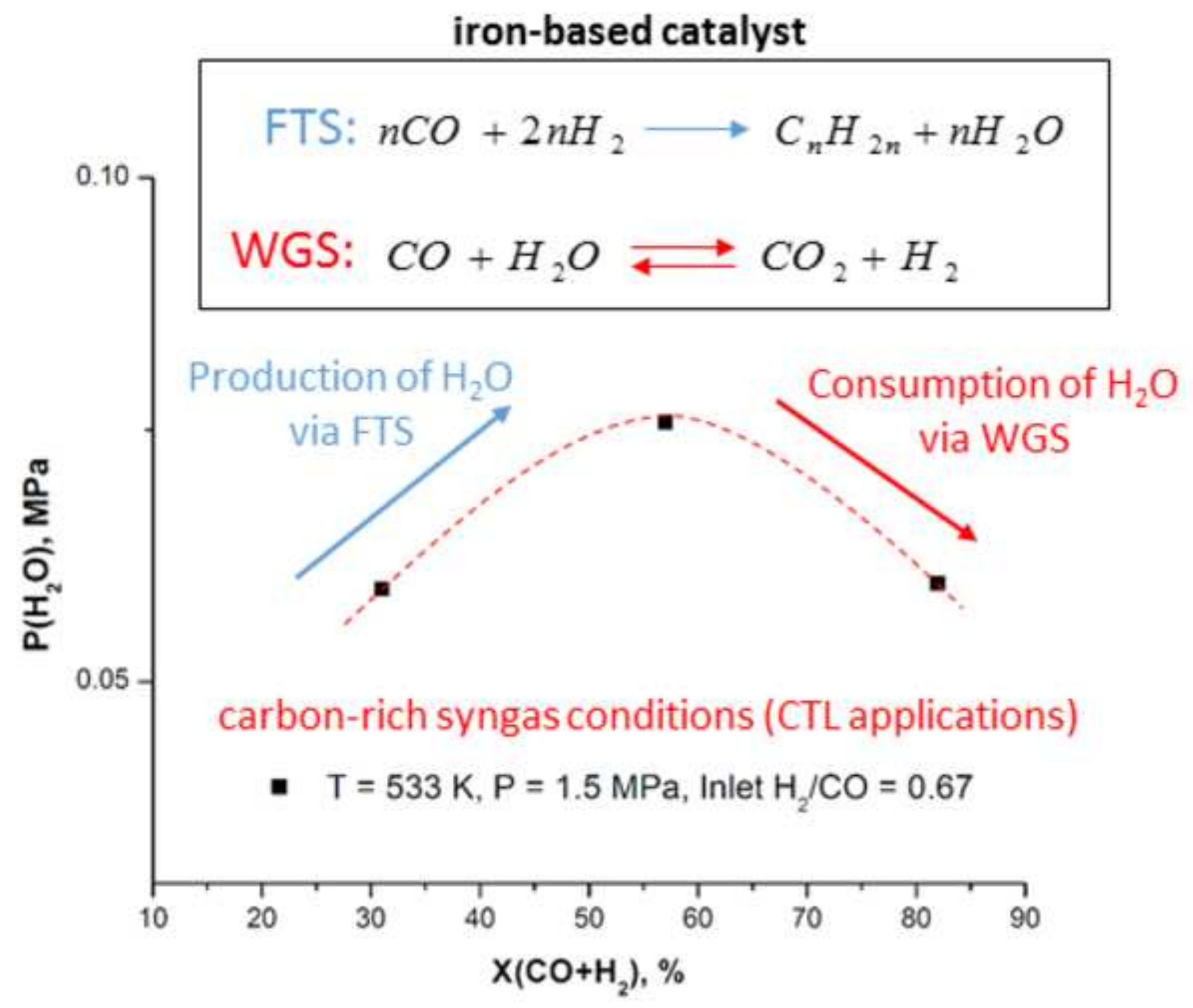

